\title{
Is the Silicone Implant actually in the Subperiosteal Pocket in Augmented Rhinoplasty?
}

\author{
Jumroon Tungkeeratichai, Sarinya Urathamakul, Chalermchai Chintrakarn, Thongchai Bhongmakapat, \\ Porncharn Saitongdee, Pisamai Orathai, Somyot Kunachak
}

\begin{abstract}
Purpose: To identify the right plane in augmented rhinoplasty to help facilitate the facial plastic surgeons in creating more natural look in oriental noses.

Materials and methods: One hundred and ten adult Thai cadavers comprising 61 males and 49 females from Department of Anatomy, Faculty of Science, Mahidol University were included in this study. Augmentation rhinoplasty with the closed technique was performed by using silicone prosthesis; then, surgical incision was done at midline from nasion to nasal tip to identify the correlation between silicone and periosteum in the area of rhinion and nasion.
\end{abstract}

Results: This study included 61 male and 49 female cadavers. At the rhinion, silicones were placed in subperiosteal plane of 65 cadavers $(59.1 \%)$ and above periosteum of 45 cadavers (40.9\%). In nasion area, silicones were successfully inserted below periosteum of 109 cadavers (99.1\%). However, silicone was placed in the supraperiosteum of only one cadaver $(0.9 \%)$.

Conclusion: Silicone can be inserted into subperiosteal layer in the area of nasion easier than in the area of rhinion. Augmented rhinoplasty by using silicone insertion in subperiosteal plane, at lease in the nasion area, makes it more natural look, stable and can prevent misalignment.

Keywords: Rhinion, Nasion, Silicone augmentation, Rhinoplasty.

\section{Source of support: Nil}

Conflict of interest: None declared

\section{INTRODUCTION}

Although the majority of rhinoplasty in Asian nose, especially Thai people, Japanese, Chinese, Korea involves augmentative procedures, the majority of Caucasian nose rhinoplasty is reduction rhinoplasty to correct 'Hump nose'. ${ }^{1,2}$ There are no definite data about the true position of silicone, either above or below the periosteum.

There are two hypotheses about the exact position. Some surgeons who believe that the silicone should be placed below periosteum. ${ }^{5}$ This is because when they use periosteal elevator in order to create a tunnel below periosteal (above nasal bone), they detect the 'bone cry' sound. On the other hand, there are surgeons who place silicone above periosteal, because it is very thin and easily torn ${ }^{3,4}$ while they are using the periosteal elevator creating a tunnel or putting silicone in the tunnel.

\section{OBJECTIVE}

To study the proper position of silicone used in augmentation rhinoplasty in correlation with the periosteal at either the rhinion or the nasion.

\section{DEFINITION}

Rhinion is the junction between upper lateral cartilage and nasal bone.

Nasion is the junction between frontal and nasal bone.

\section{MATERIALS AND METHODS}

A prospective study was done in 110 cadavers. Augmentation rhinoplasty with the closed technique was performed by using silicone prosthesis. All cases were performed by the senior author using standard surgical instruments.

Marginal incision was done along the inferior border of the lower lateral cartilage while it was extended into the superior half of the columella and then dissected below subcutaneous layer to create midline pocket. It was continued along this plane until reaching the osteocartilaginous junction. The periosteal was elevated by a periosteal elevator. The distal end of the tunnel was terminated at half way between the infrabrow and intercanthal lines. Then, silicone prosthesis was inserted with curve arterial clamp below Aufricht nasal retractor. After the augmentation rhinoplasty had been done, surgical incision was made at midline from nasion to nasal tip to identify the correlation between silicone and periosteum in the area of rhinion and nasion (Figs 1 and 2).

\section{RESULTS}

All 110 cadaveric noses were augmented by using silicone prosthesis.

At the rhinion (junction between upper lateral cartilage and nasal bone), silicone was placed above periosteum in 45 cadavers $(40.9 \%)$ and subperiosteal in 65 cadavers (59.1\%). By gender correlation, in 49 female cadavers, 


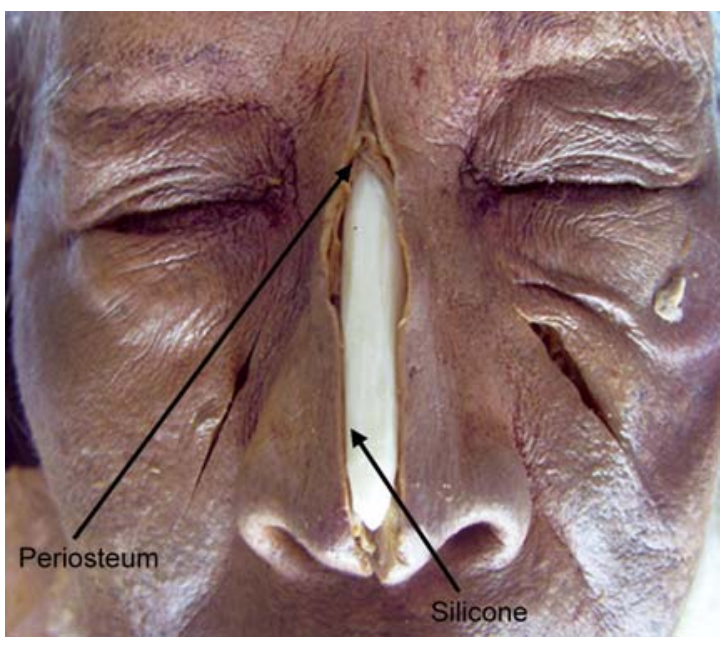

Fig. 1: Silicone position

Table 1: Number and percentage of cadavers by gender and position of silicone prosthesis at rhinion area

\begin{tabular}{lllll}
\hline \multirow{2}{*}{ Gender } & \multicolumn{3}{c}{ Position of silicone at rhinion } & \multirow{2}{*}{$\chi^{2}$-test } \\
\cline { 2 - 4 } & Below & Above & Total & \\
\hline \multirow{2}{*}{ Male } & 38 & 23 & 61 & \multirow{2}{*}{$0.582 \mathrm{NS}$} \\
& $34.50 \%$ & $20.90 \%$ & $55.50 \%$ & \\
Female & 27 & 22 & 49 & \\
& $24.50 \%$ & $20.00 \%$ & $44.50 \%$ & \\
\hline \multirow{2}{*}{ Total } & 65 & 45 & 110 & \\
& $59.10 \%$ & $40.90 \%$ & $100.00 \%$ & \\
\hline
\end{tabular}

NS: Not significant

silicone was placed above periosteum for 22 cadavers (20\%) and subperiosteum for 27 cadavers (24.5\%). From 61 male cadavers, silicone was inserted above periosteum for 23 (20.9\%) and 38 (34.5\%) for subperiosteum. A correlation between gender and silicone position at the rhinion was calculated by Fisher's exact probability test $(\alpha=0.05)$, which results in 0.582 ( $p>0.05$ ) (Table 1). From this result, it shows no statistical significance between gender and silicone position at the rhinion.

In nasion area, we found that silicone could be successfully inserted below periosteum in 109 cadavers (99.1\%). But in only 1 cadaver, silicone was placed supraperiosteum (0.9\%) (Table 2). By gender correlation, in 49 female cadavers, silicone was placed above periosteum for 1 cadaver (0.9\%) and subperiosteum for 48 cadavers (43.6\%). From 61 male cadavers, silicone was inserted into subperiosteum layer in all of them and none in female. A correlation between gender and silicone position at the nasion was calculated by Fisher's exact probability test $(\alpha=0.05)$, which results in 1.256 ( $\mathrm{p}$ > 0.05 ), and this is not significant statistically.

\section{DISCUSSION}

For oriental noses, there are many esthetic problems such as broad base, low dorsum and short nose. These are

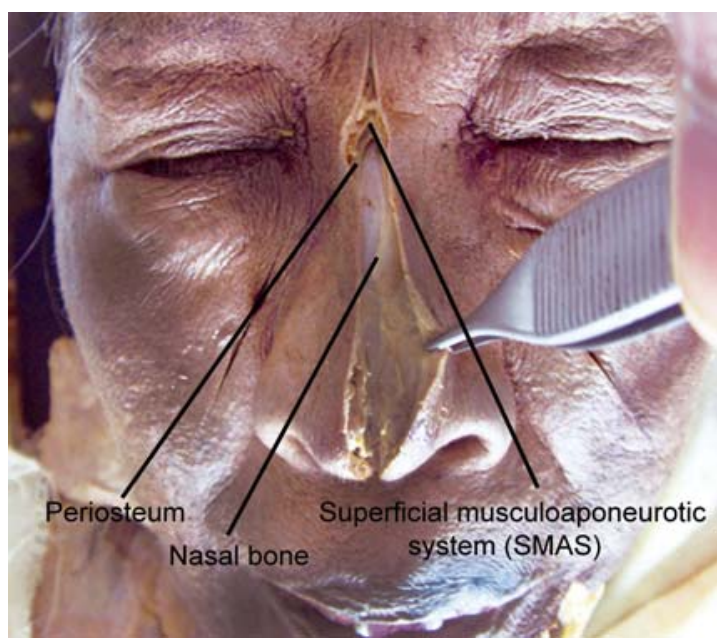

Fig. 2: Demonstration of periosteum and superficial musculoaponeurotic system

Table 2: Number and percentage of cadavers by gender and position of silicone prosthesis at nasion area

\begin{tabular}{lllll}
\hline \multirow{2}{*}{ Gender } & \multicolumn{3}{c}{ Position of silicone at rhinion } & \multirow{2}{*}{$\chi^{2}$-test } \\
\cline { 2 - 4 } & Below & Above & Total & \\
\hline \multirow{2}{*}{ Male } & 61 & 0 & 61 & \multirow{2}{*}{$1.256 \mathrm{NS}$} \\
& $55.50 \%$ & $0.00 \%$ & $55.50 \%$ & \\
Female & 48 & 1 & 49 & \\
& $43.60 \%$ & $0.90 \%$ & $44.50 \%$ & \\
\hline \multirow{2}{*}{ Total } & 109 & 1 & 110 & \\
& $99.10 \%$ & $0.90 \%$ & $100.00 \%$ & \\
\hline
\end{tabular}

NS = Not significant

commonly corrected by silicone augmentation rhinoplasty, but many of unsatisfactory issues have been mentioned. A major postoperative unsatisfaction after rhinoplasty is misalignment. It is believed that supraperiosteal layer insertion is the key of this problem. Several techniques have been published to place prosthesis in the subperiosteal layer, but it has not yet been described in which layer the prosthesis is located.

In some studies, the plane of dissection was in the midline which separates subcutaneous and muscular tissues from the cartilage and bone, creating a pocket for the dorsal graft $^{7}$ without description of silicone location. However, in some studies, the dissection was done in supraperichondrial plane at rhinion and followed by sharp periosteal elevator dissection in creating the subperiosteal tunnel over the nasal bone. ${ }^{8}$ From the study of Rojvachiranonda et $\mathrm{al}^{6}$ in Thai augmentation rhinoplasty, periosteal coverage was always incomplete and did not provide immediate implant fixation. But this study does not show the definite area of incomplete periosteal coverage or location of the augmented silicone.

From our study, it shows that silicone position was associated with periosteum which depends on the position of nose and shape of nose. However, so far there is no study regarding location of the augmented prosthesis. Therefore, 
this study is a preliminary study to define the exact location of prosthesis.

At the rhinion, in the majority of cases the silicone was placed above periosteum about $1.3 \mathrm{~cm}$ in average. ${ }^{9}$ Before it could have entered subperiosteum successfully at nasion, periosteum was disrupted. This may be because the periosteum was more tight to the nasal bone and thinner than in the rhinion area or by disruption from prosthesis insertion. The disruption length of periosteum above nasal bone was found about $0.6 \mathrm{~cm}$ in average from rhinion to nasion.

When compared to the nasion of the nose, silicone was placed into subperiosteum more successfully, because the skin, subcutaneous tissue, periosteum in this area are thicker and stronger than those in rhinion area. Therefore, in augmentation rhinoplasty the prosthesis should be placed into subperiosteum to reduce misalignment rate, and dissection along nasal bone is the most effective way to insert silicone prosthesis. We have also found that there is no statistical significance between gender and position of silicone.

\section{CONCLUSION}

Silicone could be inserted into subperiosteal layer in the area of nasion more easy than in the area of rhinion. Augmented rhinoplasty by using silicone insertion in subperiosteal plane, at lease the nasion area, makes it more natural look, stable and can prevent misalignment.

\section{ACKNOWLEDGMENTS}

The authors wish to thank Dr Worranan Prasanatikom and Professor Amnuay Thithapangha, Faculty of Medicine, Ramathibodi Hospital, Mahidol University for help with the analysis and advice during the preparation of this manuscript.

\section{REFERENCES}

1. Tardy ME Jr, Toriumi DM, Hecht DA. Philosophy and principles of rhinoplasty. In: Papel ID, Nachlas NE, editors. Facial plastic and reconstructive surgery. St. Louis, MO: Mosby; 2002. p. 369-389.

2. McCurdy JA Jr, Lam SM. Asian rhinoplasty. Cosmetic Surg Asian Face 2005;2:49.

3. Letourneau A, Daniel RK. The superficial musculoaponeurotic system of the nose. Plast Reconstr Surg 1988;82:48-57.

4. Firmin F. Discussion of Letourneau A, Daniel RK. Superficial musculoaponeurotic system of the nose. Plast Reconstr Surg 1988;82:56.
5. Stal S, Oneal RM. Evaluation and surgical approach to the osseocartilaginous vault. In: Gunter JP, Rohrich RJ, Adams WP, editors. Dallas Rhinoplasty. St. Louis, MO: Quality Medical Publishing; 2001. p. 441-469.

6. Rojvachiranonda N, Pyungtanasup K, Siriwan P, Mahatumarat C. Cadaveric study of the nasal periosteum and implant position after augmentation rhinoplasty. J Craniofac Surg 2012;23(4):1163-1165.

7. Ahn J, Honrado C, Horn C. Combined silicone and cartilage implants augmentation rhinoplasty in Asian patients. Arch Facial Surg 2004;6(2):120-123.

8. Kheang K, Park ES, Nam SM, Shin HS, Jung SG, Kin YB. Augmentation rhinoplasty with silicone implant. J Soonchunhyang Med Sci 2009;15(1):23-32.

9. Jumroon T, Thongchai B, Somyot K. Position of silicone in the augmentative rhinoplasty. Thai J Otolaryngol Head Neck Surg 2008;9(1):28-32.

\section{ABOUT THE AUTHORS}

\section{Jumroon Tungkeeratichai (Corresponding Author)}

Assistant Professor, Department of Otolaryngology, Faculty of Medicine, Ramathibodi Hospital, Mahidol University, Bangkok10400, Thailand, Phone: 0-2201-1515, Fax: 0-2354-7293, e-mail: jumroont@yahoo.com

\section{Sarinya Urathamakul}

Fellow of Facial Plastic and Reconstructive Surgery, Department of Otolaryngology, Faculty of Medicine, Ramathibodi Hospital, Mahidol University, Bangkok, Thailand

\section{Chalermchai Chintrakarn}

Associate Professor, Department of Otolaryngology, Faculty of Medicine, Ramathibodi Hospital, Mahidol University, Bangkok Thailand

\section{Thongchai Bhongmakapat}

Assistant Professor, Department of Otolaryngology, Faculty of Medicine, Ramathibodi Hospital, Mahidol University, Bangkok Thailand

\section{Porncharn Saitongdee}

Associate Professor, Department of Anatomy, Faculty of Science Mahidol University, Bangkok, Thailand

\section{Pisamai Orathai}

Assistant Professor, Department of Nursing, Faculty of Medicine Ramathibodi Hospital, Mahidol University, Bangkok, Thailand

\section{Somyot Kunachak}

Professor, Department of Otolaryngology, Faculty of Medicine Ramathibodi Hospital, Mahidol University, Bangkok, Thailand 